\title{
A semi-centralized, valveless and demand controlled ventilation system in comparison to other concepts in field tests
}

\author{
Alexander Merzkirch ${ }^{\mathrm{a}, *}$, Stefan Maas ${ }^{\mathrm{a}}$, Frank $_{\text {Scholzen }^{\mathrm{a}}}$, Daniele Waldmann $^{\mathrm{a}}$ \\ ${ }^{a}$ University of Luxembourg, Rue Richard Coudenhove Kalergi 6, L-1359 Luxembourg
}

\begin{abstract}
The idea of adapting the air supply rate to the actual demand in a building is not a new one. In commercial buildings it is already state-of-the-art to establish a demand controlled ventilation, where the level of air flow is based on sensors or time control. In residential buildings however, mechanical ventilation systems, whether centralized or decentralized, are in most cases operated in a constant modus, providing fresh air regardless if the fresh air is needed or not, even though the technology and the components needed for demand controlled ventilation exist and can be purchased at reasonable prices. In this article, results of field tests with a semi-centralized demand feedback-controlled ventilation system are shown and compared to outcomes with other demand controlled systems. The semi-centralized prototype includes decentralized fans per ventilation zone, making a room-wise ventilation possible and valves to balance the system hydraulically unnecessary. It is shown that each presented concept of demand controlled ventilation can save energy by decreasing the operational time or the mean air flow rate without compromising air quality. Concepts which make a zone- or even a room-wise control of air flow possible, showed the highest energy saving potential of up to two-thirds compared to a system operating at constant flow rates. In addition to the energy savings due to decreased operational time, the maintenance and filter costs are decreased while the user
\end{abstract}

\footnotetext{
${ }^{*}$ Corresponding author

Email address: alexander.merzkirch@uni.lu (Alexander Merzkirch)
}

Preprint submitted to Building and Environment

June 4, 2015 
comfort is increased, as natural ventilation in spring, summer and autumn may easily be added when $\Delta \mathrm{T}$ between inside and outside is small.

Keywords: elsarticle.cls, Demand controlled ventilation, Mechanical Ventilation, Energy Savings

\section{Introduction}

A demand controlled ventilation systems should automatically adapt its air flow rate to the actual demand in a building, zone or room which occupancy varies with time. Reducing the air flow means reducing heat losses, consumption of electrical energy and maintenance effort [1] 2]. At the same time, the indoor air quality is not reduced or even increased. It also increases the comfort of the user, since the system is automatically adapting to the behavior of the user. In summertime, when outside air temperature is close to inside temperature, the user may open windows or doors, instead of relying on the mechanical ventilation system. If he does so, the air exchange rate will rise quickly and normally, the mechanical ventilation is not needed anymore to ensure proper indoor air quality. This is then recognized by the demand controlled ventilation system and the fans are turned off and electrical energy is saved. Sensors can be used to evaluate the indoor air quality, which are in most cases $\mathrm{CO}_{2}$ or VOC (Volatile Organic Compounds) sensors [3, 4, 5, 6]. $\mathrm{CO}_{2}$ sensors react to human presence and activity only, while VOC sensors additionally can capture organic compounds in the room air which can be released by furniture, paint or actions like cooking or smoking. There are thousands of VOC compounds with unknown composition and origin, unless expensive measurement equipment is used. Hence, the measured VOC concentration can only be a mean value [7. In residential buildings, the use of demand controlled ventilation is not state-of-the-art yet, although there exist all necessary technology and numerous studies which show the potential of such a system [8][10]. This present study compares 3 demand controlled ventilation systems in field tests, including a semi-centralized prototype which uses decentralized fans per ventilation zone, 
making a room-wise ventilation possible. By using decentralized fans, there is no need for valves, which hydraulically balance a conventional system while causing pressure losses.

\section{Objects and Methods}

The three concepts of demand controlled ventilation analyzed in this study are:

- Centralized system in a single family home with only one $\mathrm{CO}_{2}$ sensor in the extract.

- Decentralized pair-wise operating system with a VOC Sensor per device and shutters

- Semi-centralized system with decentralized fans, shutters and VOC sensors per ventilation zone

Centralized system with $\mathrm{CO}_{2}$ sensor in extract air. The first system is a conventional centralized system, installed in a single family home which is equiped

with a $\mathrm{CO}_{2}$ sensor in the extact duct. The concentration of $\mathrm{CO}_{2}$ is continously measured and represents the mean value in the building. Hence, the specific room with an increased demand can not be located. Due to the feedback control, an increase of the $\mathrm{CO}_{2}$ concentration leads to an increased flow rate. Figure 1 shows the control algorithm for this system. There exist four operating levels for the air flow rate: Off $\left(0 \mathrm{~m}^{3} / \mathrm{h}\right)$, basic flow $\left(115 \mathrm{~m}^{3} / \mathrm{h}\right)$, nominal flow (145 $\left.\mathrm{m}^{3} / \mathrm{h}\right)$ and intensive flow $\left(176 \mathrm{~m}^{3} / \mathrm{h}\right)$. The system checks the air quality in the extract duct every 30 minutes and increases the air flow according to the sensor signal. The control algorithm of the system is shown in figure 1. The systems starts in idle mode with fans turned off. Every 30 minutes, the $\mathrm{CO}_{2}$ concentration is checked after the systems was operated on basic flow rate for 5 minutes. If the concentration is below $600 \mathrm{ppm}$, the system goes to idle again, if it is above $600 \mathrm{ppm}$, the basic flow rate is activated for 30 minutes. Then, 
the concentration is checked again. If the value is then still above $600 \mathrm{ppm}$, the systems goes to nominal flow rate until concentrations are below $600 \mathrm{ppm}$ again. If it has decreased and is now below $600 \mathrm{ppm}$ again, the system goes to idle mode. Parallel to these algorithms, the intensive flow is activated for 30 minutes, if $\mathrm{CO}_{2}$ concentrations over $800 \mathrm{ppm}$ are measured. When concentrations fall under $800 \mathrm{ppm}$ again, the nominal flow rate is activated for 30 minutes and concentrations checked again.

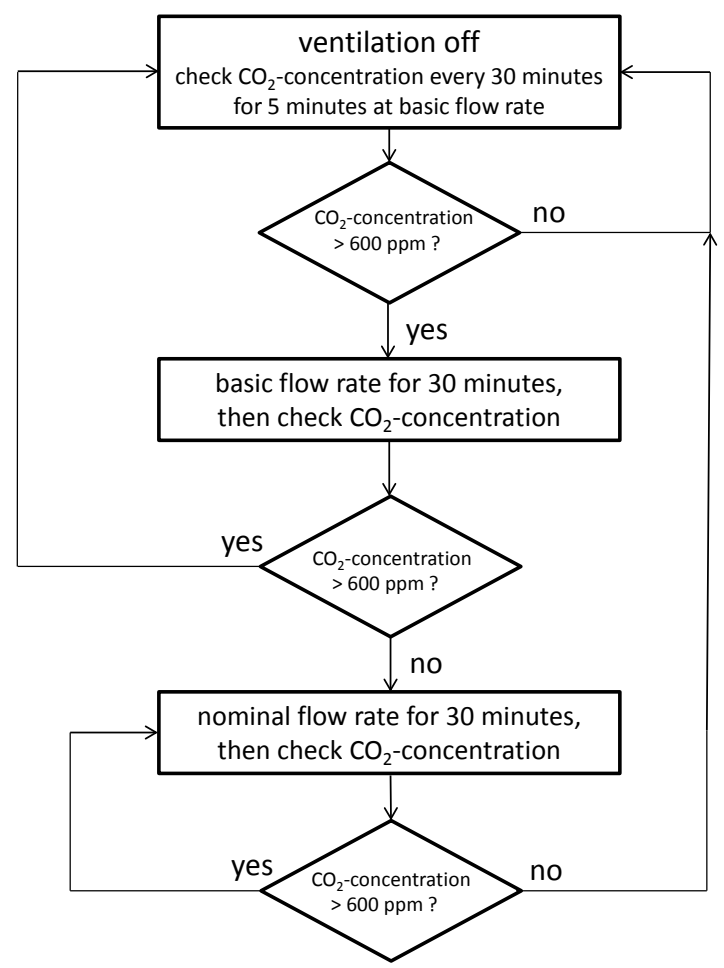

Figure 1: Control algorithm - Centralized system with $\mathrm{CO}_{2}$ sensor in extract

Decentralized pair-wise operating system with a VOC sensor. The second system uses a pair of decentralized devices with regenerative heat exchangers and one axial fan in each device. They always operate in pairs: While the first device is extracting air, its partner is supplying air. After 60 seconds, the fans reverse both their direction. In extract mode, the warm extract air heats up 
aluminium heat storage plates, while in supply mode, the gathered heat is then transferred to the supply air. Each device is equipped with a shutter, which closes when the devices are not operating. A sensor at each device captures the VOC concentrations in the rooms continously. A simple algorithm was used to control the system (Fig. 2). When the sensor detects concentrations above 600, the shutters open and the fans start running. If the concentration is below 600 for longer than 5 minutes, the device stops and the shutters close. The devices were set to a volume flow of $30 \mathrm{~m}^{3} / \mathrm{h}$.

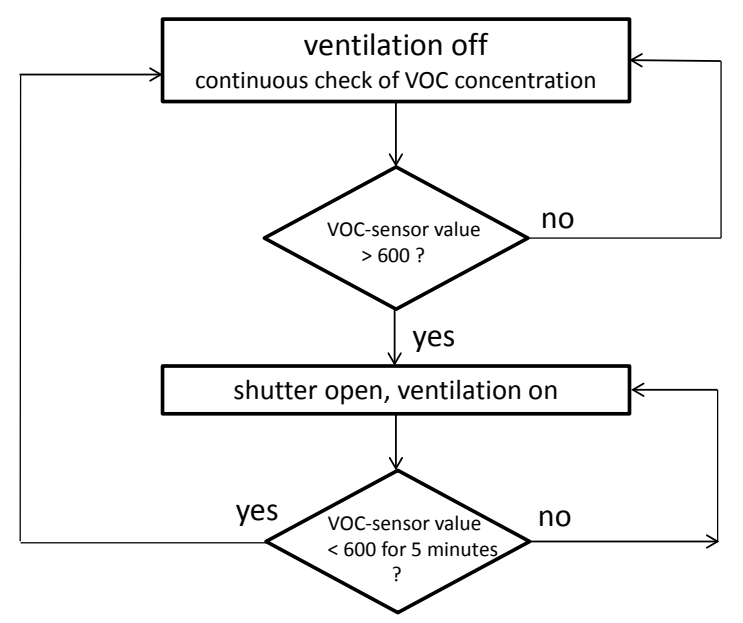

Figure 2: Control algorithm - Decentralized pair-wise operating system with a VOC sensor per device and shutters

Semi-centralized system with decentralized fans, shutters and VOC sensors per ventilation zone. In a conventional centralized system, any duct to each ventilation zone has to be balanced by valves. Valves are not only a stream resistance to the air flow, causing pressure losses which have to be overcome by the fans, they are also in a standard centralized ventilation system not able to cope with varying air flow rates. With a decreasing total air flow, the differences between the air flow in the single ducts are getting smaller and vice-versa for an increasing total air flow. Hence, with a demand controlled centralized ventilation system, the supply of the correct air flow rates to any individual zone or room 
is only possible with automatically controlled volume flow balancing.

But with this semi-centralized concept, we avoid this problem by using decentralized fans for each ventilation zone, making a zone-wise feed-back control possible. The decentralized fans are placed in a box, from where the single ducts to the ventilation zones are leading (Fig. 3). Each single duct can be opened or closed by automated shutters. VOC sensors are placed behind the extract fans of each zone. Beside this box we used a recuperative heat recovery and filter device from a conventional centralized system from which the main outdoor and exhaust air ducts are leading to the envelope of the building.

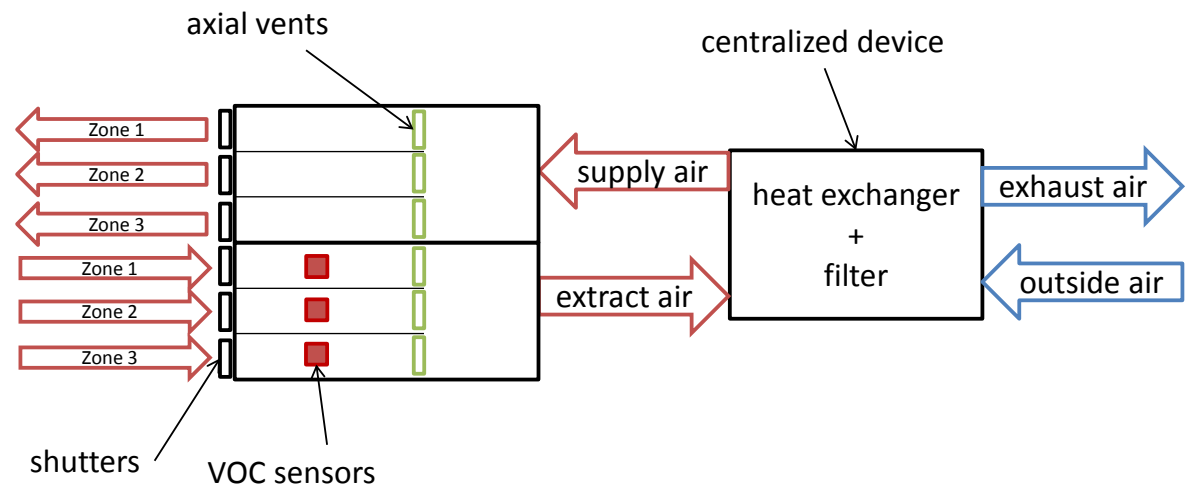

Figure 3: Semi-centralized system with decentralized fans, shutters and VOC sensors per ventilation zone

The system was installed for testing purposes in a dwelling with three ventilation zones: Bedroom $\left(40 \mathrm{~m}^{3}\right)$, living room $\left(40 \mathrm{~m}^{3}\right)$ and bathroom $\left(10 \mathrm{~m}^{3}\right)$.

Every 30 minutes, all zones were activated, shutters opened and the fans started running (Fig. 4). After 5 minutes of ventilating, the sensor values were read. If the VOC sensor value was above 800, the zone was kept activated for 25 more minutes. If the sensor values was below 800 , the zone was shut down for 25 minutes. Using this algorithm, the system was active for at least 10 minutes per hour, providing a basic air flow of $1 / 6$ of the total air flow. In our case this was $6 \mathrm{~m}^{3} / \mathrm{h}$ per zone. The supplied fresh air flow per zone was $36 \mathrm{~m}^{3} / \mathrm{h}$ when 
all three zones were active.

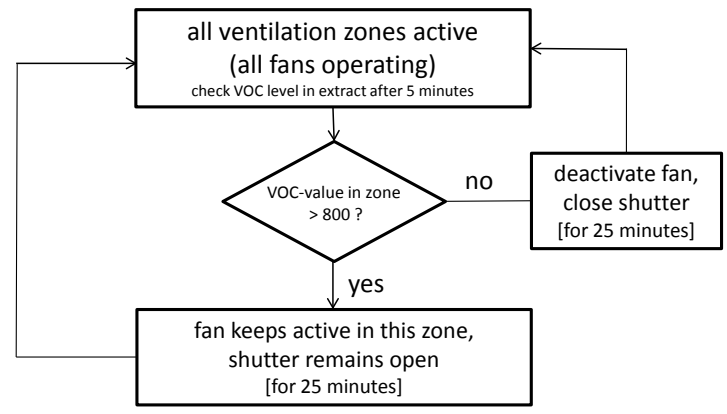

Figure 4: Control Algorithm - Semi-centralized system with decentralized fans, shutters and VOC sensors per ventilation zone

\section{Results}

Centralized system with $\mathrm{CO}_{2}$ Sensor in extract. During the heating season 2013/14 the operation of the centralized demand controlled system with a $\mathrm{CO}_{2}$ sensor in the extract duct was monitored over a period of six months. During $43 \%$ of the time, the system was in idle mode and $42 \%$ of the time it was operating at basic flow rate of $115 \mathrm{~m}^{3} / \mathrm{h}$ and specific fan power of $0,186 \mathrm{Wh} / \mathrm{m}^{3}$. The $\mathrm{CO}_{2}$ level in the extract duct could be kept under 700 ppm during $93 \%$ of the time which is a sign for sufficient indoor air quality. The two occupants showed normal presence over the meauserement period.

Decentralized pair-wise operating system with a VOC Sensor. The operation time of the system could be reduced by $40 \%$ which correspondingly means that the measured VOC value was below 600 ppm during $60 \%$ of the measurement time. This results in lower heating losses and electricity consumption. The sepecific fan power was measurend with $0,52 \mathrm{Wh} / \mathrm{m}^{3}$ which is too high due to an oversized power supply in our prototype. Using more efficient power supply and motors to control the shutters this value can probably be reduced to a typical value of $0,3 \mathrm{Wh} / \mathrm{m}^{3}$. 
Semi-centralized system with decentralized fans, shutters and VOC sensors per ventilation zone. The semi-centralized concept showed the highest operation time reduction. In the living room the system was active $50 \%$ of the time, the zone "'bathroom"' was operating $46,5 \%$ of the time and the bedroom was ventilated only $30 \%$ of the measurement time. The zonewise concept leads to the highest savings in ventilation losses and electricity consumption. The measured total volume flow was $53 \mathrm{~m}^{3} / \mathrm{h}$ for one activated zone, $81 \mathrm{~m}^{3} / \mathrm{h}$ for two activated zones and $108 \mathrm{~m}^{3} / \mathrm{h}$ for three activated zones. The specific fan power was 0,43 to $0,5 \mathrm{Wh} / \mathrm{m}^{3}$ depending on how much zones were active. This value can probably be reduced to a typical value of about $0,3 \mathrm{Wh} / \mathrm{m}^{3}$ by using radial fans which show an optimum of efficiency at around $30 \mathrm{~m}^{3} / \mathrm{h}$ instead of the currently used axial fans and by reducing the flow resistances in the used ducts and the box. The $\mathrm{CO}_{2}$ concentrations were simultanously measured in the zones and could be kept under $1000 \mathrm{ppm}$ in all rooms during the measurement period. The evolution of $\mathrm{CO}_{2}$ and VOC concentration for two typical nights can be seen in figure 5 . The VOC concentrations have a more volatile behaviour, but in principal show the same peaks and lows as the $\mathrm{CO}_{2}$ concentration. It can be seen, that as soon as a person enters the bedroom (around 11 p.m.), the sensors recognize a demand of fresh air in the room and the system is kept active. The maximum reaction time of 25 minutes can be considered as sufficient to maintain a good indoor air quality. The frequency distribution of VOC values during the measurement period of 60 days is displayed in figure 6 . The threshold of 800 also marks the time of the system being active. During $80 \%$ of the time captured, the VOC sensor value was below 1000, which shows the proper functionality of the algorithm. Only in certain moments, values rose up to more than 2000 which probably happened, when the user came close to the sensor or more people were present. 


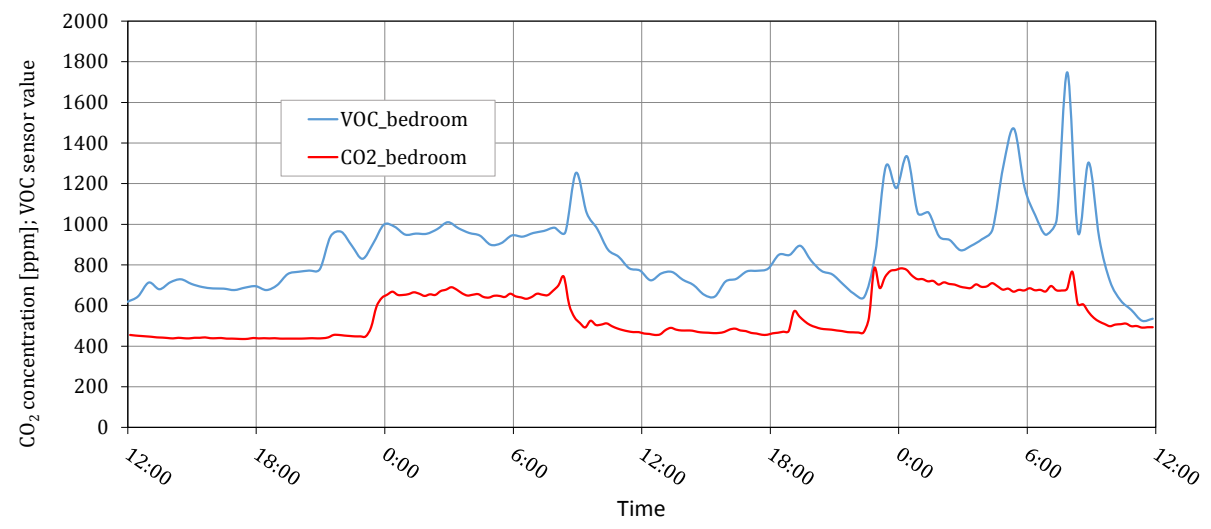

Figure 5: $\mathrm{CO}_{2}$ and VOC concentration for two nights in a dwelling with $\mathrm{n}_{50}$ value of $0.51 / \mathrm{h}$, ventilated with semi centralized system

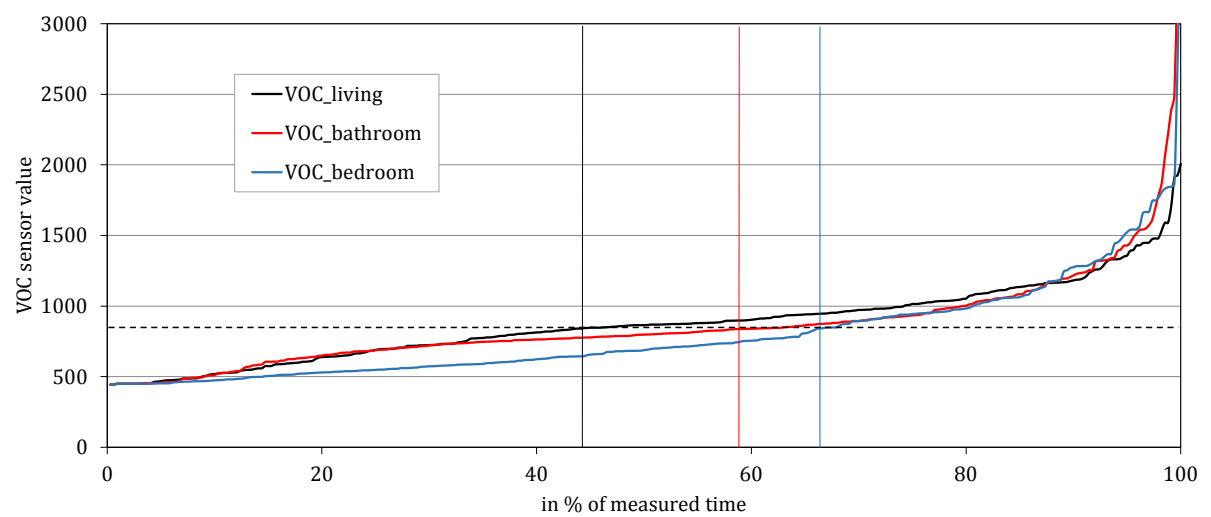

Figure 6: Duration curve of VOC values during the measurement period of 60 days for semi centralized system

Improvements and further developments.

- To improve the accuracy and reliability of the system, an additional VOC sensor could be placed in the outdoor air duct to compare indoor and outdoor concentrations.

- Insted of VOC sensors in each exhaust duct there could be only one VOC 
sensor in the centralized exhaust duct behind the box. The single channels could the be activated one after another to check the VOC concentrations in each zone. Sensor costs could thus be lowered.

- Flow resistances could be reduced by designing the box and the ducts more stream-efficiently.

- By the use of radial ventilators instead of axial ones, the specific fan power can be reduced and a higher pressure stability provided. The new fans should be chosen with a maximum efficiency around $30 \mathrm{~m}^{3} / \mathrm{h}$.

- The number of revolutions should be adjustable in order to ensure a constant basic ventilation rate during winter time instead of a pulsed operation.

Primary Energy Demand (PED). The annual primary energy demand has been calculated with input parameters measured in the field tests for a typical single family home in Luxembourg of $150 \mathrm{~m}^{2}$ net area with a total volume flow of $140 \mathrm{~m}^{3} / \mathrm{h}$. The overall demand without heat recovery is converted to primary energy.

$$
P E D_{n}=\dot{V} \cdot \rho \cdot \Delta T \cdot c_{p} \cdot f_{h} \cdot f_{p, h} \cdot t_{h p}
$$

with:

$\dot{V}=$ volume flow $\left[\mathrm{m}^{3} / \mathrm{h}\right]$

$\rho=$ density of air $\left[\mathrm{kg} / \mathrm{m}^{3}\right]$

$c_{p}=$ specific heat capacity of air $[\mathrm{kJ} / \mathrm{kgK}]$

$\Delta T=$ mean $\Delta T$ between in- and outside during heating period $[\mathrm{K}]$

$t_{h p}=$ duration of heating period $[\mathrm{h}]$

$f_{h}=$ production factor heating

$f_{p, h}=$ primary energy factor heating 
In case of a mechanical ventilation system, the heat recovery of the extract air can reduce this demand, but the used electrical energy has to be added. If the ventilation system is used outside the heating period, $\Delta \mathrm{T}$ is set to 0 , while the electrical consumption for the fans still has to be considered.

PED $D_{\text {konstant }}=\dot{V} \cdot \rho \cdot \Delta T \cdot c_{p} \cdot\left(1-\eta_{h r}\right) \cdot f_{h} \cdot f_{p, h} \cdot t_{h p}+\dot{V} \cdot S F P \cdot f_{p, e l} \cdot 8760 h$

with:

$\eta_{h r}=$ heat recovery rate

$S F P=$ specific fan power $\left[\mathrm{Wh} / \mathrm{m}^{3}\right]$

$f_{p, e l}=$ primary energy factor electricity

$t_{h p} \quad=$ duration of heating period $[\mathrm{h}]$

A demand driven system can work on different volume flow level. Furthemore, the energy consumption during stand-by modus must be considered.

$$
\begin{aligned}
P E D_{d c v} & =P_{s b} \cdot f_{p, E l} \cdot t_{s b} \\
& +\sum_{i=1}^{n}\left(\dot{V}_{i}\left(\rho \cdot \Delta T \cdot c_{p} \cdot\left(1-\eta_{h r}\right) \cdot f_{p, W}+S F P_{i} \cdot f_{p, E l}\right)\right) \cdot t_{i, \text { heatingperiod }} \\
& +\sum_{i=1}^{n}\left(\dot{V}_{i} \cdot S F P_{i} \cdot f_{p, E l}\right) \cdot t_{i, s}
\end{aligned}
$$

with:

$P_{s b} \quad=$ power consumption in stand-by modus $[\mathrm{W}]$

$t_{s b} \quad=$ duration in stand-by per year $[\mathrm{h}]$

$n=(1, . ., i)=$ volume flow level $\dot{V}_{i}$ and specific fan power $S L A_{i}$

$t_{i, h p} \quad=$ operational time on volume flow level i during heating period $[\mathrm{h}]$

$t_{i, s} \quad=$ operational time on volume flow level i during summer [h]

while:

$$
t_{s b}+\sum_{i=1}^{n} t_{i, h p}+\sum_{i=1}^{n} t_{i, s}=8760 h
$$


The following assumptions were used for the input parameters:

Table 1: Assumptions for input parameters for calculation of PED

\begin{tabular}{c|c} 
volume flow $\dot{V}$ & $140 \mathrm{~m}^{3} / \mathrm{h}($ detached house) \\
\hline density of air $\rho$ & $1,204 \mathrm{~kg} / \mathrm{m}^{3}$ \\
\hline$\Delta T$ & $15 \mathrm{~K}$ \\
\hline specific heat capacity of air & $1,005 \mathrm{~kJ} / \mathrm{kgK}$ \\
\hline heat recovery rate & 0,75 for all systems \\
\hline production factor heating $f_{h}$ & 1,25 \\
\hline primary energy factor heating $f_{p, h}$ & 1,1 \\
\hline primary energy factor electrical energy $f_{p, e l}$ & see table 2 \\
\hline duration of heating period & 2,7 \\
\hline
\end{tabular}

The specific fan power (SFP) is assumed according to table 2 The values for conventional systems are based on mean values derived in field tests with 20 centralized and 60 decentralized ventilation systems. The lower value for decentralized system, to the most part, results from the lower pressure resistance, since the devices are directly placed in the specific rooms and no ductwork is needed. The value for the demand driven centralized system with $\mathrm{CO}_{2}$ is lower than for a conventional system, since it is operated at lower mean volume flow, due to the variation of the fan speed and the cubic relation between the volume flow and the power. Since the fan speed of the decentralized and semicentralized systems are not controlled yet, we assume a value of $0,3 \mathrm{Wh} / \mathrm{m}^{3}$ which can possibly be lowered in future when using more efficient power supply, electric motor and adjustable fan speed. The assupmtions could therefore be called conservative. 


\begin{tabular}{c|c} 
Table 2: Specific Fan Power values used for PED calculations \\
system & SFP $\left[\mathrm{Wh} / \mathrm{m}^{3}\right]$ \\
\hline centralized & 0,4 \\
decentralized & 0,2 \\
centralized, DCV, $\mathrm{CO}_{2}$ in exhaust air & 0,3 \\
decentralized, DCV, VOC & 0,3 \\
semi-centralized, DCV, VOC & 0,3
\end{tabular}

As can be seen in figure 7, the primary energy use is reduced by around $50 \%$ when using demand controlled concepts compared to constant driven systems. The first bar corresponds to the case of no mechanical ventilation, but the same air flow of $140 \mathrm{~m}^{3} / \mathrm{h}$. That means, no heat recovery takes place, but also no electrical energy is used. Simply, the ventilation heat losses are displayed for natural ventilation at a volume flow of $140 \mathrm{~m}^{3} / \mathrm{h}$. This, of course, is only theoretical value. In practice, the user will probably either under- or overventilate. Especially for the worst case, bedroom at night during wintertime, an appropriate natural ventilation is almost impossible to establish.

The bars "'centralized"' and "'decentralized"' count for throughout the year constantly operated ventilation systems with heat recovery. The last three bars represent the three concepts which were tested in our projects. The highest savings could be achieved with the semi-centralized system being able to ventilate each zone seperately. But every other demand controlled concept is preferable to any constant driven system. At a volume flow of $140 \mathrm{~m}^{3} / \mathrm{h}$, or in other words, an air exchange of around $0.9 \mathrm{1} / \mathrm{h}$, the use of a mechanical ventilation system with heat recovery is more efficient than natural ventilation as expected at such high volume flows. Lower volume flows will of course reduce the disadvantage of mechanical ventilation in general, but also especially of demand controlled systems, but will on the other hand possibly reduce the indoor air quality. 


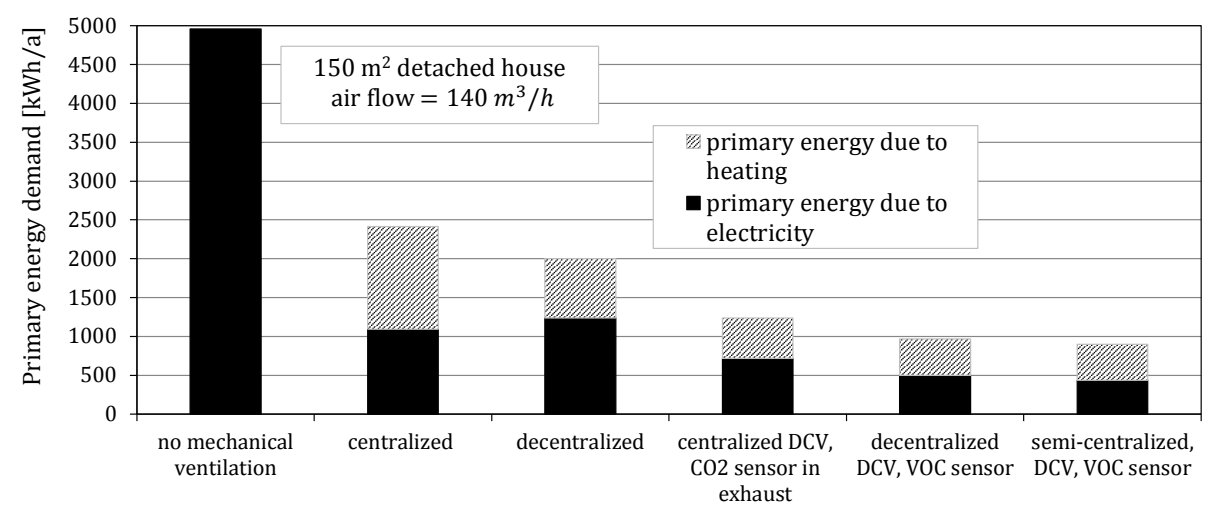

Figure 7: Primary Energy use in a typical single family home

Costs. Often the question is raised, if a demand controlled ventilation was more expensive than conventional system. It is, in terms of investment, but can pay off in the long term, if the costs for heat and electricity are lowered respectively. We compared calculational costs over a lifespan of 25 years and considered all costs which can occur during the lifetime of a mechanical ventilation system. Investment costs include all components, the devices, ductwork, sensors, etc. and the installation and commissioning. Energy costs include ventilation heat losses and electrical energy. For the maintenance costs, the yearly change of filters and a complete ductcleaning is considered. The values are derived from manufacturers and settled bills form the field tests. In figure 8 it is shown, that a demand controlled ventilation system is able to work at lower costs than a conventional system. A demand controlled centralized system, show about 25 $\%$ less total costs than a conventional centralized system, despite the higher initial costs. Same counts for the decentralized systems. The new developed semi-centralized system is supposed to be slightly more expensive than the two other demand controlled concepts. This is because of the more complex technology and more parts. In industrial production, the prices for this system could drop significantly though. After all, a mechanical ventilation system is always more expensive than a natural ventilation. The saved costs derived by the en- 
ergy savings cannot pay off the high investment of such a system. However, a mechanical ventilation system enhances the user comfort and can therefore be seen as useful investment. In addition, it should be emphasized, that the costs for maintenance are as high as the costs for energy due to high filter costs.

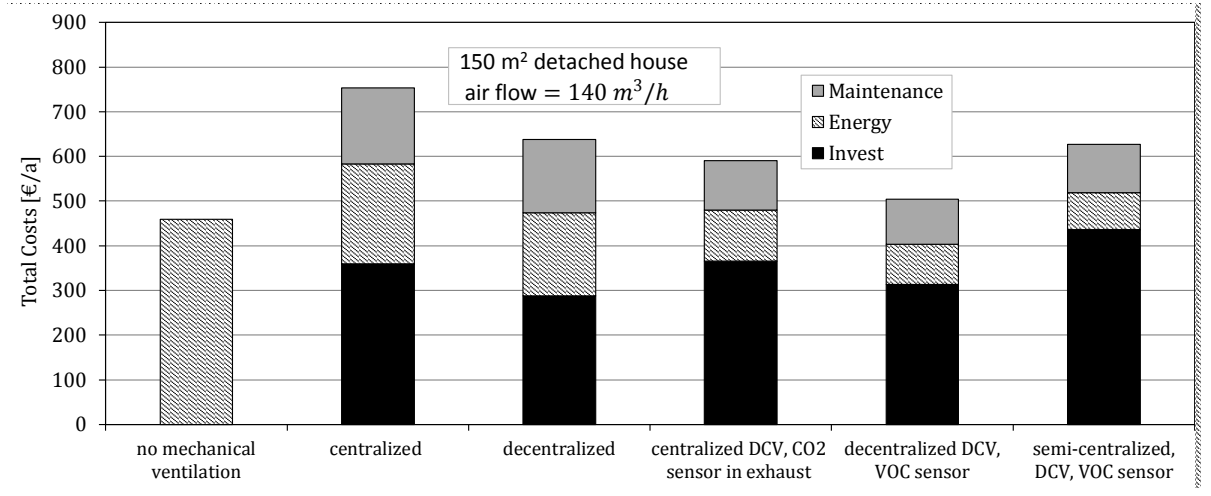

Figure 8: Total costs of different ventilation concepts

\section{Discussion and Conclusion}

Three concepts of demand controlled ventilation were tested and compared. While it is only possible to define one ventilation zone with concept no.1, the two other concepts make it possible to define variable ventilation zones throughout the building. Since occupants are usually not present in all zones at any time, higher savings in terms of heat and electrical energy are possible. Concept no.3 is new in residential ventilation technology and uses decentralized fans to ventilate each ventilation zone seperately. In addition to the savings due to the zone-wise ventilation, valves in terms of in- and outlets are not needed any more, resulting in lower pressure losses.

During tests in typical dwellings in Luxembourg it could be shown that die operational time of the ventilation systems could be reduced by around $50 \%$ without compromising the air quality, the semi-centralized concept showing the highest operation reduction by about $65 \%$. All systems and VOC sensors 
worked reliably and reacted to user presence in short time. The reduction of operational time leads to savings in primary energy, to lower operational costs and furthermore to decreased filter and maintenance costs in comparison to conventional systems. Since costs for sensors and electronics dropped in the last years, calculations show that the operation of a demand controlled ventilation system is no longer limited to research projects or commercial buildings. For the next years it could be expected, that on the way to EPBD 2020, demand controlled ventilation technology could find its way into european households.

Acknowledgements. The authors acknowledge the high value contribution of the Ministry of Economy, Luxembourg and the Société Nationale des Habitations à Bon Marché (S.N.H.B.M.) which assisted with personnel, material, installations and gave valuable technical knowledge and assessment. Supported by the Fonds National de la Recherche, Luxembourg (PhD-FSTC-2015-05)

\section{Bibliography}

[1] J. Laverge, N. V. D. Bossche, N. Heijmans, A. Janssens, Energy saving potential and repercussions on indoor air quality of demand controlled residential ventilation strategies, Building and Environment 46 (2011) 14971503. doi:10.1016/j.buildenv.2011.01.023.

[2] K. Shan, Y. Sun, S. Wang, C. Yan, Development and in-situ validation of a multi-zone demand-controlled ventilation strategy using a limited number of sensors, Building and Environment 57 (2012) 28-37. doi:10.1016/j. buildenv.2012.03.015.

[3] T. R. Nielsen, C. Drivsholm, Energy efficient demand controlled ventilation in single family houses, Energy and Buildings 42 (2010) 1995-1998. doi: $10.1016 / j$.enbuild.2010.06.006

[4] W. J. Fisk, A. T. de Almeida, Sensor-based demand-controlled ventilation: a review, Energy and Buildings 29 (1998) 35-45. doi:10.1016/ S0378-7788(98)00029-2. 
[5] M. K. Kim, H. Leibundgut, Performance of novel ventilation strategy for capturing co2 with scheduled occupancy diversity and infiltration rate, Building and Environment 89 (2015) 318-326. doi:10.1016/j.buildenv. 2015.02 .012

[6] Z. Sun, S. Wang, Z. Ma, In-situ implementation and validation of a co2based adaptive demand-controlled ventilation strategy in a multi-zone office building, Building and Environment 46 (2011) 124-133. doi:10.1016/j. buildenv.2010.07.008

[7] W. Ye, D. Won, X. Zhang, A preliminary ventilation rate determination methods study for residential buildings and offices based on voc emission database, Building and Environment 79 (2014) 168-180. doi:10.1016/j. buildenv.2014.05.009.

[8] M. H. Sherman, I. S. Walter, Meeting residential ventilation standards through dynamic control of ventilation systems, Energy and Buildings 43 (2011) 1904-1912. doi:10.1016/j.enbuild.2011.03.037.

[9] D. Johansson, H. Bagge, L. Lindstrii, Measurements of occupancy levels in multi-family dwellingsapplication to demand controlled ventilation, Energy and Buildings 43 (2011) 2449-2455. doi:10.1016/j.enbuild.2011.05. 031.

[10] V. Pavlovas, Demand controlled ventilation: A case study for existing swedish multifamily buildings, Energy and Buildings 36 (2004) 1029-1034. doi:10.1016/j.enbuild.2004.06.009. 